\title{
Effect of ruminal plastic bags on haematological and biochemical parameters of sheep and goats
}

\author{
H. R. OTSYINA*, P. G MBUTHIA, J. NGUHIU-MWANGI, E. G. M. MOGOA \& W. O. \\ OGARA \\ (H. R. O.: School of Veterinary Medicine, College of Basic and Applied Sciences, University of \\ Ghana, Legon; P. G. M.: Department of Veterinary Pathology, Microbiology and Parasitology, \\ Faculty of Veterinary Medicine, University of Nairobi, Kenya; J. N., E. G. M. M. \& H. R. O.: De- \\ partment of Clinical Studies, Faculty of Veterinary Medicine, University of Nairobi, Kenya; W. O. \\ O.: Department of Public Health, Pharmacology and Toxicology, Faculty of Veterinary Medicine, \\ University of Nairobi, Kenya) \\ *Corresponding author's email: rhotsyina@ug.edu.gh /hotsyina64@yahoo.com_
}

\begin{abstract}
A study was carried out with the objective of determining the haematological and blood biochemical parameters in sheep and goats with plastic bags in the rumen for a period of 42 days. This was to indicate the possible influence of plastic bags in the rumen on blood parameters. 16, one-year old castrate Dorper sheep with a mean body weight of $26.8 \mathrm{~kg}( \pm 0.3 \mathrm{~kg})$ and 16 one-year old castrate small East African goats with a mean weight of $24.5 \mathrm{~kg}( \pm 0.3 \mathrm{~kg})$ were used for the study. The 16 sheep and 16 goats were divided into 4 groups of 4 animals each $(n=4)$. Three groups of each species were implanted with $129 \mathrm{~g}, 258 \mathrm{~g}$ and $387 \mathrm{~g}$ of plastic bags, respectively, in the rumen through rumenotomy and the fourth group of each species was control on which rumenotomy was done but with no implanting of plastic bags. Blood samples were obtained by jugular venipuncture from all sheep and goats every 2 weeks for analysis. The only haematological parameter that had significant change was platelets, which significantly $(p<0.05)$ increased in both sheep and goats with plastic bags in the rumen. However, mean values of erythrocytes, packed cell volume, haemoglobin and mean corpuscular volume decreased but not significantly in the sheep and goats with plastic bags in the rumen. The sheep and goats with plastic bags in the rumen had hyponatraemmia, hypochloridaemia and decreased aspartate aminotransferase enzyme activity. The changes observed in haematological and biochemical parameters could be an indication of adverse effects on the production and well-being of sheep and goats that ingest these plastic bags. These finding may be of diagnostic importance in cases of rumen impaction with indigestible foreign bodies, particularly, plastic bags.
\end{abstract}

Original scientific paper. Received 24 Apr 17; revised 02 Nov 17

\section{Introduction}

The rumen is the largest compartment of the fore stomachs in ruminants (Radostitis et al., 2009). Over $80 \%$ of the energy supply for sheep and goats is obtained through the fermentation of feed materials in the rumen (Randall et al., 2002). Interferences with the process of fermentation and absorption of volatile fatty acids

Ghana Jnl Agric. Sci. 53, 5 -16

GJAS is an Open Access Journal and distributed under the terms of the Creative Commons (CC) License [CC BY 4.0] 
as a result of accumulation of indigestible foreign bodies in the rumen deprives the animal of valuable nutrients for its survival (Igbokwe et al., 2003). Rumen impaction resulting from ingestion and accumulation of indigestible foreign bodies is reported to be one of the most common causes of gastrointestinal disorders in sheep and goats (Abdullahi et al., 1984; Radostitis et al., 2009).

A number of factors have been incriminated as predisposing factors for ingestion of indigestible foreign materials by sheep and goats. These include starvation during long periods of feed scarcity (Igbokwe et al., 2003), mineral and nutritional deficiencies (Radostitis et al., 2009), depraved appetite due to continuous exposure to indigestible materials (Vijaya et al., 2012) and environmental pollution with non-biodegradable materials (Hailat et al., 1997; Abdullahi et al., 2004; Gurashi et al., 2009). Clinical symptoms of impaction of the rumen with indigestible foreign bodies in sheep and goats are reported to vary widely from mild indigestion to life threatening systemic signs (Gyang, 1991; Otsyina et al., 2016). However, complications depend on the nature and quantity of the foreign bodies (Calfee and Manning, 2002), as well as the duration of impaction.

Changes in haematological and biochemical parameters are indicators of physiological disturbances and pointers to various disease conditions and have been used both at clinical and subclinical levels to provide diagnostic and prognostic aid in some disease conditions (Jain, 1980). Haematological changes associated with clinical impaction of the rumen with indigestible foreign bodies in small ruminants include significant decrease in haematocrit, haemoglobin and erythrocyte counts (Elsa and Oneyili, 2002; Daramola et al., 2005; Bakhiet, 2008; Akirinmade and Akirinde, 2012). Decrease in mean corpuscular volume (MCV) and mean corpuscular haemoglobin concentration (MCHC) have also been reported (Akirinmade and Akirinde, 2012). However, Bakhiet (2008) found significant increase in mean corpuscular haemoglobin $(\mathrm{MCH})$ and mean corpuscular haemoglobin concentration (MCHC) indicative of microcytic hyperchromic anaemia in sheep impacted with foreign bodies in Sudan. Serum biochemical changes described in sheep and goats whose rumen were impacted with indigestible foreign bodies include decreased serum chloride, sodium, potassium, calcium, glucose and total proteins (Igbokwe et al., 2003; Akirinmade and Akirinde, 2012). However, these reports were on parameters of animals that died, in which the duration of impaction and the type of material causing the impaction were not clearly stated.

Plastic bags or polythene bags are the most common indigestible materials ingested by sheep and goats (Omidi et al., 2012; Sileshi et al., 2013; Otsyina et al., 2014). The prevalence of these plastic bags in the rumen of small ruminats has been described in different geographical regions of the world (Roman and Hiwot, 2010; Sileshi et al., 2013). Phenomenal rise in prevalence of rumen impaction with plastic bags has been associated with increased demand and use of these bags in urban and rural areas (Ghurashi et al., 2009; Tesfaye et al., 2012).

However, the effect of plastic bags in the rumen on the physiology of sheep and goats, which is indicative of the wellbeing of the animals, has not been fully elucidated and remains highly speculative. For instance, the quantities of plastic materials in the rumen producing clinical effects on the animals is not known. Also the time taken for such effects to be manifested has not been reported. The paucity of information in this respect is due to the fact that small ruminants are considered to be more selective in 
their feeding and therefore less likely to ingest large quantities of foreign materials compared to cattle (Hailat et al., 1997). This paper reports the haematological and biochemical changes associated with presence of specific quantities of plastic bags in the rumen of sheep and goats for a period of 42 days and also compares these effects between the two animal species.

\section{Materials and methods}

\section{Ethical approval}

Animal use was approved by the Biosafety, Animal use and Ethics Committee (BAEC) of the Faculty of Veterinary Medicine, University of Nairobi, Kenya, according to international standards of animal use in research; clearance certificate number: 11250313.

\section{Experimental animals}

The experimental animals included 16 one year-old castrated Dorper sheep and 16 one year-old castrated small East Africa goats. The sheep had a mean body weight of $26.8 \pm 0.3$ $\mathrm{kg}$ with average body condition score of 3.5 \pm 0.5 (on a scale of 1-5), while the goats had mean body weight of $24.5 \pm 0.3 \mathrm{~kg}$ and average body condition score of $3.0 \pm 0.5$ (on a scale of 1-5). The animals were housed in groups of four (4) for the whole period of the experiment and allowed 6 weeks to acclimatize to the environment and feed. The animals were subjected to routine physical examination over the acclimatization period to note any signs of disease.

The animals were assigned to 4 experimental groups for each species $(n=4)$, using stratified random sampling based on body weight of the animals, such that the mean weight of animals in each of the experimental groupings was not statistically different. Three of the groups, had $129 \mathrm{~g}, 258 \mathrm{~g}$ and $387 \mathrm{~g}$ of plastic bags respectively, implanted into the rumen. Rumenotomy procedure was done as previously described by Hendrickson (2007). The fourth group for each species, both sheep and goats served as control, on which rumenotomy was done but no plastic bags were implanted in the rumen. The plastic bags implanted were the non-perforated small soft polythene bags (KEBS Industries Ltd, Nairobi, Kenya). Each poly bag measured $167 \mathrm{~mm}$ x $290 \mathrm{~mm}$ in size, 30 micrometers thick and a packet of 100 pieces weighed $129 \mathrm{~g}$. These were the most common type of plastic bags found in the rumen of sheep and goats during an abattoir study carried out prior to this study (Otsyina et al., 2015). The sheep and goats in all the groups were monitored daily for a period of 42 days' post implantation. Blood Samples for haematological and biochemical analysis were collected from all sheep and goats by jugular venipuncture before and after implantation of the plastic bags into the rumen which was considered as day 0 , and thereafter on days 14, 28 and 42 .

\section{Haematological analysis}

Blood for haematology was collected from each animal into $5 \mathrm{ml}$ vacutainer tubes (BD Vacutainers Systems, Plymouth, UK), containing di-potassium salt of ethylenediaminetetraacetic acid (EDTA) powder as an anticoagulant. Haematological analysis was done using the Auto analyzer MELET SCHLOESINL (MS) 4 (Melet Schloesinl Laboratories, ONSY, France). White blood cell (WBC) differential counts were done manually under a light microscope, from thin blood smears stained with Giemsa stain as describe by Cheesbrough (2000).

\section{Serum biochemical analysis}

Blood for biochemical analysis was collected from each animal into a $10 \mathrm{ml}$ vacutainer tubes without anticoagulant. The blood samples were allowed to stand on the bench between 45 min- 
utes and 1 hour for adequate clotting. Serum was separated by centrifuging each sample at $3000 \mathrm{rpm}$ for 3 minutes. The serum was then transferred into $1.5 \mathrm{ml}$ vials and stored at $-20^{\circ} \mathrm{C}$ until analyzed. Serum biochemical analyses were done using the Humalyzer 2000 spectrophotometer (Human Gesellschaft fur Biochemica und Digonostica, Wiesbaden, Germany).

\section{Statistical analysis}

The data obtained were subjected to student's $t$-test (GraphPad Prism Statistical Software, Inc, California, USA). Means and standard errors were calculated for comparison of values at day 42 with those of day 0 as well as control groups. Significance was set at $p<0.05$.

\section{Results}

Changes in haematological parameters in the sheep

Haematological parameters of sheep whose rumen was implanted with plastic bags in the rumen and those of the control are presented on Table 1. Mean values of red blood cell (RBC) count, packed cell volume (PCV), haemoglobin $(\mathrm{Hb})$, mean corpuscular haemoglobin concentration (MCHC), white blood cells (WBC) count and lymphocyte count decreased slightly in sheep implanted with $129 \mathrm{~g}$ of plastic bags. The decrease in $\mathrm{RBC}, \mathrm{PCV}, \mathrm{Hb}, \mathrm{MCHC}$ and WBC were observed on day 42 . The mean values of mean corpuscular volume (MCV), plate- let (PTL), neutrophils and eosinophils for this group increased over the study period. The observed changes in the haematological parameters were not significantly different compared with the mean values before implantation of the plastic bags in the rumen as well as those of the control (Table 1).

In the sheep whose rumen were implanted with $258 \mathrm{~g}$ of plastic bags, mean values of $\mathrm{RBC}, \mathrm{Hb}$ and $\mathrm{MCV}$ decreased while the values of $\mathrm{MCH}, \mathrm{MCHC}$ and PTL increased over the study period. But all the changes in the mean values of various blood parameters, except PTL were, however, not statistically significant $(p>0.05)$ when compared with mean values at day 0 as well as the control. These values also did not differ from those of the sheep with 129 $\mathrm{g}$ of plastic bags in the rumen (Table 1).

For the sheep whose rumen was implanted with $387 \mathrm{~g}$ of plastic bags, the mean values of RBC and MCV decreased slightly, while the mean values of $\mathrm{MCH}, \mathrm{MCHC}$, PTL, WBC, lymphocytes, neutrophils and eosinophils increased slightly at day 42 . Changes in the mean values of PCV and $\mathrm{MCV}$ were inconsistent over the period. They also did not differ significantly from those of the sheep with $129 \mathrm{~g}$ and $258 \mathrm{~g}$ of plastic bags, except that the PTL significantly increased in the sheep in these groups (Table 1). 
TABLE 1

Mean ( \pm S.E.M) haematological values of sheep implanted with $129 \mathrm{~g}, 258 \mathrm{~g}$ and $387 \mathrm{~g}$

of plastic bags in the rumen for 42 days

\begin{tabular}{|c|c|c|c|c|c|c|c|c|}
\hline \multirow{3}{*}{ Parameters } & \multicolumn{8}{|c|}{ Quantity of plastic bags } \\
\hline & \multicolumn{2}{|c|}{$0 \mathrm{~g}$ (Control) } & \multicolumn{2}{|c|}{$129 \mathrm{~g}$} & \multicolumn{2}{|c|}{$258 \mathrm{~g}$} & \multicolumn{2}{|c|}{$387 \mathrm{~g}$} \\
\hline & Day 0 & Day 42 & Day 0 & Day 42 & Day 0 & Day 42 & Day 0 & Day 42 \\
\hline $\mathrm{RBC}(\mathrm{M} / \mu \mathrm{L})$ & $9.42 \pm 0.14$ & $8.74 \pm 0.38$ & $9.0 \pm 0.3$ & $7.8 \pm 0.5$ & $10.2 \pm 0.5$ & $6.9 \pm 1.3$ & $9.3 \pm 0.0$ & $6.7 \pm 1.3$ \\
\hline $\mathrm{Hb}(\mathrm{g} / \mathrm{dL})$ & $10.88 \pm 0.13$ & $10.58 \pm 0.72$ & $9.5 \pm 0.2$ & $8.8 \pm 0.6$ & $11.2 \pm 0.5$ & $9.5 \pm 1.3$ & $10.6 \pm 0.3$ & $9.5 \pm 1.3$ \\
\hline PCV (\%) & $28.98 \pm 0.66$ & $26.63 \pm 1.42$ & $26.4 \pm 1.1$ & $23.9 \pm 2.2$ & $29.6 \pm 1.4$ & $27.2 \pm 4.2$ & $27.1 \pm 0.5$ & $27.2 \pm 4.2$ \\
\hline MCV (fL) & $29.20 \pm 1.06$ & $30.43 \pm 0.56$ & $29.1 \pm 0.3$ & $31.3 \pm 0.3$ & $29.6 \pm 0.7$ & $28.5 \pm 0.7$ & $30.3 \pm 0.7$ & $28.5 \pm 0.7$ \\
\hline $\mathrm{MCH}(\mathrm{pg})$ & $11.05 \pm 0.09$ & $11.98 \pm 0.32$ & $11.1 \pm 0.1$ & $10.4 \pm 0.3$ & $10.9 \pm 0.2$ & $11.7 \pm 0.6$ & $10.5 \pm 0.2$ & $11.7 \pm 0.6$ \\
\hline $\mathrm{MCHC}(\mathrm{g} / \mathrm{dL})$ & $37.98 \pm 0.86$ & $39.60 \pm 0.78$ & $36.9 \pm 0.1$ & $36.4 \pm 0.9$ & $37.5 \pm 0.7$ & $41.4 \pm 1.5$ & $34.0 \pm 2.8$ & $41.4 \pm 1.5$ \\
\hline $\operatorname{PTL}\left(10^{3} / \mu \mathrm{L} / \mu \mathrm{l}\right)$ & $249.8 \pm 36.15$ & $206.3 \pm 16.63$ & $160.3 \pm 51.4$ & $253.3 \pm 41.1^{*}$ & $221.8 \pm 39.5$ & $240.0 \pm 34.2^{*}$ & $271.5 \pm 42.0$ & $240.0 \pm 34.2^{*}$ \\
\hline WBC $\left(10^{3} / \mu \mathrm{L} / \mu \mathrm{L}\right)$ & $13.21 \pm 3.87$ & $8.27 \pm 0.61$ & $8.5 \pm 1.55$ & $5.74 \pm 0.43$ & $6.00 \pm 0.61$ & $8.24 \pm 1.1$ & $10.57 \pm 1.8$ & $8.24 \pm 1.1$ \\
\hline Lymphocytes $\left(10^{3} / \mu \mathrm{L}\right)$ & $36.50 \pm 4.41$ & $44.50 \pm 7.22$ & $47.5 \pm 6.1$ & $46.3 \pm 5.4$ & $49.5 \pm 4.3$ & $35.7 \pm 4.7$ & $50.3 \pm 8.6$ & $35.7 \pm 4.7$ \\
\hline Neutrophils $\left(10^{3} / \mu \mathrm{L}\right)$ & $62.75 \pm 3.83$ & $55.00 \pm 7.08$ & $51.6 \pm 6.5$ & $53.3 \pm 5.2$ & $50.3 \pm 4.1$ & $60.0 \pm 5.2$ & $49.8 \pm 8.7$ & $60.0 \pm 5.29$ \\
\hline Eosinophils $\left(10^{3} / \mu \mathrm{L}\right)$ & $0.00 \pm 0.00$ & $0.00 \pm 0.00$ & $0.0 \pm 0.0$ & $0.7 \pm 0.7$ & $0.0 \pm 0.0$ & $0.7 \pm 0.7$ & $0.0 \pm 0.0$ & $0.7 \pm 0.7$ \\
\hline Monocytes $\left(10^{3} / \mu \mathrm{L}\right)$ & $0.25 \pm 0.25$ & $0.00 \pm 0.00$ & $0.0 \pm 0.0$ & $0.3 \pm 0.3$ & $0.0 \pm 0.0$ & $0.0 \pm 0.0$ & $0.0 \pm 0.0$ & $0.0 \pm 0.0$ \\
\hline Basophils $\left(10^{3} / \mu \mathrm{L}\right)$ & $0.50 \pm 0.50$ & $0.00 \pm 0.00$ & $0.0 \pm 0.0$ & $0.0 \pm 0.0$ & $0.0 \pm 0.0$ & $0.0 \pm 0.0$ & $0.0 \pm 0.0$ & $0.0 \pm 0.0$ \\
\hline Nucleated RBCs $\left(\mathrm{mm}^{3}\right)$ & $0.00 \pm 0.00$ & $0.00 \pm 0.00$ & $0.0 \pm 0.0$ & $0.0 \pm 0.0$ & $0.0 \pm 0.0$ & $0.0 \pm 0.0$ & $0.0 \pm 0.0$ & $0.0 \pm 0.0$ \\
\hline
\end{tabular}

Key: $\quad$ RBC: red blood cells; PCV: packed cell volume; Hb: haemoglobin concentration; MCV: mean corpuscular volume; $\mathrm{MCH}$ : mean corpuscular haemoglobin; MCHC: mean corpuscular haemoglobin concentration; PTL: platelets; WBC: white blood cell.

*Differences in mean values significant at 95\% level $(\mathrm{p}<0.05)$ (from baseline values and control).

Changes in haematological parameters in the goats

Haematological parameters of the goats whose rumen were implanted with plastic bags and the control are presented in Table 2 . The goats, implanted with $129 \mathrm{~g}$ of plastic bags had significantly $(p<0.05)$ lower mean values of $\mathrm{RBC}$, PCV, MCH and PTL in blood samples collected at day 42 compared to day 0 and the control (Table 2). The mean values of WBC, lymphocytes and neutrophils had a slight decrease, but these did not significantly differ from the mean values at day 0 or the control. (Table 2).

Changes in blood biochemical parameters in the sheep

Biochemical parameters for the sheep implanted with plastic bags and the control are presented on Table 3. For the sheep whose rumen were implanted with $129 \mathrm{~g}$ of plastic bags, there was a significant $(p<0.01)$ decrease in the mean values of chloride $(\mathrm{Cl})$ in blood samples collected at day 42 post implantation. This is an indication that the mean values of chloride had decreased from an initial value of $144.3 \pm 10.5$ $\mathrm{mg} / \mathrm{dL}$ to $64.0 \pm 4.9 \mathrm{mg} / \mathrm{dL}$ (Table 3). Mean value of aspartate aminotransferase (AST) at day 42 was higher than at day 0 as well as that of the control, but not statistically significant (Table 3). A non-significant decrease was also observed in the mean values of glucose in this group of sheep at day 42 post implantation.

In the group of sheep implanted with 258 $\mathrm{g}$ of plastic bags, a decrease in mean value of sodium was observed by day 42 ; the mean had decreased significantly $(p<0.05)$ from 132.7 $\pm 5.7 \mathrm{mmol} / \mathrm{L}$ at day 0 to $95.7 \pm 5.3 \mathrm{mmol} / \mathrm{L}$ by day 42 . The mean value of AST had also decreased significantly $(p<0.001)$ from 360.1 $\pm 95.6 \mathrm{UI} / \mathrm{L}$ at day 0 to $261.1 \pm 84.7 \mathrm{UI} / \mathrm{L}$ at day 
42. A significant decrease $(p<0.001)$ was observed in the mean value of chloride, from $138.2 \pm$ $24.5 \mathrm{mg} / \mathrm{dL}$ at day 0 to $41.0 \pm 7.7 \mathrm{mg} / \mathrm{dL}$.

TABLE 2

Mean ( \pm S.E.M) haematological values of goats implanted with $129 \mathrm{~g}, 258 \mathrm{~g}$ and $387 \mathrm{~g}$ of plastic bags in the rumen for 42 days

\begin{tabular}{|c|c|c|c|c|c|c|c|c|}
\hline \multirow{3}{*}{ Parameters } & \multicolumn{7}{|c|}{ Quantity of plastic bags } & \multirow[b]{2}{*}{$387 \mathrm{~g}$} \\
\hline & \multicolumn{2}{|c|}{ og (Control) } & \multicolumn{2}{|r|}{$129 \mathrm{~g}$} & \multicolumn{2}{|r|}{$258 \mathrm{~g}$} & & \\
\hline & Day 0 & Day 42 & Day 0 & Day 42 & Day 0 & Day 42 & Day 0 & Day 28 \\
\hline $\mathrm{RBC}(\mathrm{M} / \mu \mathrm{L})$ & $13.35 \pm 0.32$ & $13.40 \pm 0.67$ & $13.26 \pm 0.21$ & $10.13 \pm 0.62^{*}$ & $13.10 \pm 0.19$ & $14.09 \pm 0.21$ & $15.10 \pm 0.65$ & $16.25 \pm 1.20$ \\
\hline $\mathrm{Hb}(\mathrm{g} / \mathrm{dL})$ & $9.93 \pm 0.18$ & $9.23 \pm 0.34$ & $9.75 \pm 0.12$ & $7.75 \pm 0.61$ & $9.35 \pm 0.26$ & $10.63 \pm 0.38$ & $9.90 \pm 0.32$ & $9.86 \pm 0.12$ \\
\hline PCV (\%) & $21.35 \pm 1.45$ & $21.20 \pm 1.13$ & $21.85 \pm 0.85$ & $16.50 \pm 1.51^{*}$ & $21.45 \pm 0.32$ & $22.23 \pm 0.24$ & $24.23 \pm 1.04$ & $25.15 \pm 0.88$ \\
\hline $\mathrm{MCH}(\mathrm{pg})$ & $7.63 \pm 0.45$ & $6.86 \pm 0.21$ & $7.35 \pm 0.77$ & $7.60 \pm 0.15^{*}$ & $6.53 \pm 0.75$ & $7.43 \pm 0.18$ & $6.53 \pm 0.11$ & $6.20 \pm 0.15$ \\
\hline $\operatorname{MCHC}(\mathrm{g} / \mathrm{dL})$ & $46.98 \pm 2.67$ & $43.65 \pm 1.35$ & $46.13 \pm 3.91$ & $47.05 \pm 1.07$ & $40.83 \pm 0.95$ & $49.08 \pm 1.28$ & $40.33 \pm 0.57$ & $38.15 \pm 0.89$ \\
\hline $\operatorname{PTL}\left(10^{3 / \mu \mathrm{l})}\right.$ & $273.0 \pm 65.92$ & $217.8 \pm 33.53$ & $221.8 \pm 58.98$ & $104.0 \pm 16.45^{*}$ & $207.0 \pm 31.08$ & $257.5 \pm 62.04 *$ & $170.0 \pm 7.67$ & $176.5 \pm 14.16$ \\
\hline WBC $\left(10^{3} / \mu / \mathrm{L}\right)$ & $14.97 \pm 2.00$ & $11.84 \pm 0.90$ & $14.16 \pm 1.25$ & $14.22 \pm 2.72$ & $9.24 \pm 1.24$ & $15.53 \pm 1.05$ & $13.14 \pm 0.33$ & $12.89 \pm 2.16$ \\
\hline Lymphocytes $\left(10^{3 / \mu \mathrm{L})}\right.$ & $43.50 \pm 5.81$ & $53.50 \pm 1.85$ & $48.25 \pm 4.80$ & $47.25 \pm 10.09$ & $44.50 \pm 3.86$ & $44.00 \pm 3.16$ & $44.75 \pm 4.31$ & $44.00 \pm 2.48$ \\
\hline Neutrophils $\left(10^{3} / \mu \mathrm{L}\right)$ & $55.25 \pm 3.77$ & $50.25 \pm 5.36$ & $55.25 \pm 4.31$ & $52.25 \pm 10.13$ & $51.75 \pm 4.80$ & $58.50 \pm 2.50$ & $56.50 \pm 5.81$ & $63.75 \pm 7.77$ \\
\hline Eosinophils $\left(10^{3} / \mu \mathrm{L}\right)$ & $0.00 \pm 0.00$ & $0.00 \pm 0.00$ & $0.00 \pm 0.00$ & $0.00 \pm 0.00$ & $0.00 \pm 0.00$ & $0.00 \pm 0.00$ & $0.00 \pm 0.00$ & $0.00 \pm 0.00$ \\
\hline Monocytes $\left(10^{3} / \mu \mathrm{L}\right)$ & $0.00 \pm 0.00$ & $0.00 \pm 0.00$ & $0.00 \pm 0.00$ & $0.00 \pm 0.00$ & $0.00 \pm 0.00$ & $0.00 \pm 0.00$ & $0.00 \pm 0.00$ & $0.00 \pm 0.00$ \\
\hline Basophils $\left(10^{3} / \mu \mathrm{L}\right)$ & $0.00 \pm 0.00$ & $0.00 \pm 0.00$ & $0.00 \pm 0.00$ & $0.00 \pm 0.00$ & $0.00 \pm 0.00$ & $0.00 \pm 0.00$ & $0.00 \pm 0.00$ & $0.00 \pm 0.00$ \\
\hline Nucleated RBCs $\left(\mathrm{mm}^{3}\right)$ & $0.00 \pm 0.00$ & $0.00 \pm 0.00$ & $0.00 \pm 0.00$ & $0.00 \pm 0.00$ & $0.00 \pm 0.00$ & $0.00 \pm 0.00$ & $0.00 \pm 0.00$ & $0.00 \pm 0.00$ \\
\hline
\end{tabular}

Key: $\quad$ RBC: red blood cells; PCV: packed cell volume; Hb: haemoglobin concentration; MCV: mean corpuscular volume; $\mathrm{MCH}$ : mean corpuscular haemoglobin; MCHC: mean corpuscular haemoglobin concentration; PTL: platelets; WBC: white blood cell.

Differences in mean values significant at $95 \%$ level $(\mathrm{p}<0.05)$ (from baseline values and control).

TABLE 3

Mean ( \pm S.E.M) biochemical values of sheep implanted with $129 \mathrm{~g}, 258 \mathrm{~g}$

and $387 \mathrm{~g}$ of plastic bags in the rumen for 42 days

\begin{tabular}{|c|c|c|c|c|c|c|c|c|}
\hline \multirow{3}{*}{ Parameters } & \multicolumn{8}{|c|}{ Quantity of plastic bags } \\
\hline & \multicolumn{2}{|c|}{$0 \mathrm{~g}$ (Control) } & \multicolumn{2}{|c|}{$129 \mathrm{~g}$} & \multicolumn{2}{|c|}{$258 \mathrm{~g}$} & \multicolumn{2}{|c|}{$387 \mathrm{~g}$} \\
\hline & Day 0 & Day 42 & Day 0 & Day 42 & Day 0 & Day 42 & Day 0 & Day 42 \\
\hline Calcium (mg/dL) & $9.8 \pm 0.5$ & $9.0 \pm 0.5$ & $9.2 \pm 0.7$ & $9.4 \pm 0.9$ & $10.5 \pm 0.2$ & $9.2 \pm 0.1$ & $8.3 \pm 1.1$ & $8.7 \pm 0.8$ \\
\hline Sodium $(\mathrm{mmol} / \mathrm{dL})$ & $126.9 \pm 7.7$ & $161.9 \pm 16.1$ & $129.1 \pm 8.7$ & $168.5 \pm 12.3$ & $132.7 \pm 5.7$ & $95.7 \pm 5.3^{*}$ & $150.4 \pm 21.1$ & $86.9 \pm 1.1 *$ \\
\hline Potassium $(\mathrm{mmol} / \mathrm{dL})$ & $5.5 \pm 0.3$ & $3.9 \pm 0.3$ & $5.3 \pm 0.2$ & $6.0 \pm 0.4$ & $6.17 \pm 0.1$ & $5.6 \pm 0.6$ & $4.5 \pm 0.4$ & $5.3 \pm 0.8$ \\
\hline Phosphorus (mg/dL) & $6.2 \pm 0.5$ & $4.4 \pm 0.2$ & $6.0 \pm 0.6$ & $5.3 \pm 0.2$ & $6.5 \pm 0.1$ & $5.0 \pm 0.3$ & $6.1 \pm 0.2$ & $3.8 \pm 1.4$ \\
\hline Chloride $(\mathrm{mg} / \mathrm{dL})$ & $145.7 \pm 8.5$ & $145.3 \pm 33.6$ & $144.3 \pm 10.5$ & $64.0 \pm 4.9^{* *}$ & $138.2 \pm 24.6$ & $41.0 \pm 7.7^{* *}$ & $147.8 \pm 11.6$ & $41.8 \pm 1.4^{* * *}$ \\
\hline $\operatorname{AST}(\mathrm{UI} / \mathrm{L})$ & $339.4 \pm 74.5$ & $346.7 \pm 64.7$ & $311.3 \pm 91.6$ & $393.7 \pm 47.3$ & $360.1 \pm 95$ & $261.1 \pm 84.7 * * *$ & $260.2 \pm 35.3$ & $101.0 \pm 9.2 * * *$ \\
\hline $\operatorname{ALT}(\mathrm{UI} / \mathrm{L})$ & $26.9 \pm 9.6$ & $21.8 \pm 10.5$ & $17.4 \pm 3.1$ & $21.4 \pm 2.8$ & $17.4 \pm 0.7$ & $21.7 \pm 5.8$ & $28.7 \pm 1.9$ & $16.3 \pm 3.9$ \\
\hline Total bilirubin (mg/dL) & $0.2 \pm 0.0$ & $0.14 \pm 0.0$ & $0.6 \pm 0.1$ & $0.1 \pm 0.0$ & $0.3 \pm 0.5$ & $0.1 \pm 0.0$ & $0.3 \pm 0.07$ & $0.2 \pm 0.0$ \\
\hline Direct bilirubin $(\mathrm{mg} / \mathrm{dL})$ & $0.1 \pm 0.1$ & $0.08 \pm 0.0$ & $0.1 \pm 0.0$ & $0.10 \pm 0.0$ & $0.1 \pm 0.1$ & $0.1 \pm 0.0$ & $0.00 \pm 0.0$ & $0.2 \pm 0.1$ \\
\hline $\mathrm{BUN}(\mathrm{mg} / \mathrm{dL})$ & $15.6 \pm 0.6$ & $18.4 \pm 1.0$ & $17.2 \pm 2.0$ & $18.2 \pm 3.2$ & $17.8 \pm 4.9$ & $17.6 \pm 4.9$ & $37.7 \pm 0.6$ & $27.7 \pm 0.7$ \\
\hline Creatinine (mg/dL) & $1.4 \pm 0.9$ & $1.4 \pm 35.1$ & $1.4 \pm 0.1$ & $1.4 \pm 0.3$ & $1.3 \pm 0.1$ & $1.6 \pm 0.9$ & $1.4 \pm 0.1$ & $1.4 \pm 0.2$ \\
\hline Albumin $(\mathrm{mg} / \mathrm{dL})$ & $32.9 \pm 2.2$ & $41.3 \pm 0.6$ & $35.8 \pm 30.3$ & $47.1 \pm 5.7$ & $36.3 \pm 3.7$ & $35.1 \pm 1.7$ & $32.1 \pm 1.2$ & $36.7 \pm 4.5$ \\
\hline Total protein $(\mathrm{mg} / \mathrm{dL})$ & $70.5 \pm 3.7$ & $62.9 \pm 6.5$ & $75.7 \pm 11.7$ & $61.9 \pm 2.2$ & $60.3 \pm 18.1$ & $67.1 \pm 3.5$ & $63.9 \pm 1.7$ & $67.8 \pm 5.9$ \\
\hline Glucose (mg/dL) & $81.5 \pm 1.5$ & $83.8 \pm 9.1$ & $80.7 \pm 3.8$ & $65.8 \pm 4.6$ & $87.4 \pm 5.6$ & $68.7 \pm 7.4$ & $85.1 \pm 4.1$ & $70.2 \pm 5.3$ \\
\hline
\end{tabular}

Key: AST: aspartate aminotransferase; ALT: alanine aminotransferase; BUN: blood urea nitrogen.

*Differences in mean values significant at $\mathrm{p}<0.05$ (from baseline values and control).

** Differences in mean values significant at $\mathrm{p}<0.01$ (from baseline values and control).

*** Differences in mean values significant at $\mathrm{p}<0.001$ (from baseline values and control).

The decrease in mean values of chloride was also significant $(p<0.001)$ compared to that of the control. Mean values of glucose decreased, but not significantly $(p>0.05)$ from $87.4 \pm 5.6$ 
to $68.7 \pm 7.4 \mathrm{mg} / \mathrm{dl}$ in these animals; a trend similar to what was observed in the group of sheep with $129 \mathrm{~g}$ of plastic bags.

In the sheep implanted with $387 \mathrm{~g}$ of plastic bags, a significant $(p<0.05)$ decrease in the mean value of sodium was observed from 150.4 $\pm 21.1 \mathrm{mmol} / \mathrm{L}$ at day 0 to $86.9 \pm 1.1 \mathrm{mmol} / \mathrm{L}$ at day 42. Significant $(p<0.001)$ decreases were observed in the mean values of chloride and Aspartate aminotransferase (AST). Chloride decreased $(p<0.001)$ from a mean value of $147.8 \pm 11.6 \mathrm{mg} / \mathrm{dL}$ at day 0 to $41.8 \pm 1.4 \mathrm{mg} /$ $\mathrm{dL}$ at day 42 , while AST decreased $(p<0.001)$ from $260.2 \pm 35.3 \mathrm{UI} / \mathrm{L}$ at day 0 to101.0 \pm 9.2 $\mathrm{UI} / \mathrm{L}$ at day 42 (Table 3 ). The decrease in the mean values of sodium, chloride and AST were also significantly different $(p<0.001)$ from the mean values of the control. Mean values of glucose decreased but not significantly $(p>0.05)$ from $85.1 \pm 4.1$ to $70.2 \pm 5.3 \mathrm{mg} / \mathrm{dl}$ similar to what was observed in sheep with $129 \mathrm{~g}$ and 258 $\mathrm{g}$ of plastic bags in the rumen.

\section{Changes in blood biochemical parameters in}

the goats

Biochemical parameters in the goats whose rumen were implanted with plastic bags and the control are presented in Table 4. For goats in group implanted with $129 \mathrm{~g}$ of plastic bags, the mean value of sodium decreased significantly $(p<0.001)$ from $236.1 \pm 7.6 \mathrm{mmol} / \mathrm{L}$ at day 0 to $165.6 \pm 32.2 \mathrm{mmol} / \mathrm{L}$ at day 42 . Mean value of chloride also decreased significantly $(p<$ 0.001 ) from $109.1 \pm 27.0 \mathrm{mg} / \mathrm{dL}$ at day zero to $67.1 \pm 26.9 \mathrm{mg} / \mathrm{dL}$ at day 42 (Table 4). These changes in the mean values of sodium and chloride were significantly $(p<0.001)$ different from the mean values in the control.

In the group of goats implanted with $258 \mathrm{~g}$ of plastic bags, mean values of calcium significantly $(p<0.001)$ decreased from $261.4 \pm 5.7$ to $184.0 \pm \mathrm{mg} / \mathrm{dL}$, chloride from $104.3 \pm 25.2$ to $59.0 \pm 27.0 \mathrm{mg} / \mathrm{dL}, \mathrm{AST}$ from $184.9 \pm 42.4$ to $543.2 \pm 34.8 \mathrm{UI} / \mathrm{L}$ at day 42 post implantation. These changes in the mean value were also significantly $(p<0.001)$ different compared to the control. The mean value of glucose increased significantly $(p<0.001)$ from an initial value of $62.4 \pm 10.0 \mathrm{mg} / \mathrm{dL}$ at day 0 to $124.7 \mathrm{mg} / \mathrm{dL}$ at day 42 in these group of goats (Table 4).

In the group of goats whose rumen were implanted with $387 \mathrm{~g}$ of plastic bags, mean values of sodium and chloride decreased significantly ( $p<0.001)$, while the values of AST and glucose increased $(p<0.001)$ by day 42 post implantation of the plastic bags. Mean value of sodium decreased from $279.0 \pm 30.2 \mathrm{mmol} / \mathrm{L}$ at day 0 to $184.0 \pm 11.3 \mathrm{mmol} / \mathrm{L}$, while mean values of chloride decreased from $107.8 \pm 34.3$ $\mathrm{mg} / \mathrm{dL}$ at day 0 to $51.0 \pm 29.4 \mathrm{mg} / \mathrm{dL}$ at day 42 . The mean value of AST increased from 140.4 $\pm 9.0 \mathrm{IU} / \mathrm{L}$ at day 0 to $497.3 \pm 21.9 \mathrm{IU} / \mathrm{L}$ by day 42 , while the mean values of glucose significantly increased from $73.7 \pm 6.5 \mathrm{mg} / \mathrm{dL}$ at day 0 to $124.7 \pm 5.5 \mathrm{mg} / \mathrm{dL}$ by day 42 (Table 4 ).

\section{Discussion}

The slight decrease observed in mean values of RBC, PCV, $\mathrm{Hb}$ and MCV compares closely with the significant decrease reported previously in sheep that had clinical impaction of the rumen after natural ingestion of indigestible foreign bodies (Akirinmade et al., 1988; Mayer et al., 1992; Bakhiet, 2008). However, it is neither reported of the length of time these indigestible materials had been in the rumen nor the quantity that was present.

The findings further contrast the increase in $\mathrm{MCV}$ and $\mathrm{MCHC}$ reported previously in sheep found with plastic bags in the rumen in slaughter houses (Bakhiet, 2008). 
TABLE 4

Mean ( \pm S.E.M) biochemical values of goats implanted with $129 \mathrm{~g}, 258 \mathrm{~g}$

and $387 \mathrm{~g}$ of plastic bags in the rumen for 42 days

\begin{tabular}{|c|c|c|c|c|c|c|c|c|}
\hline \multirow{2}{*}{ Parameters } & \multicolumn{8}{|c|}{ Quantity of plastic bags } \\
\hline & Day 0 & Day 42 & Day 0 & Day 42 & Day 0 & Day 42 & Day 0 & Day 42 \\
\hline Calcium (mg/dL) & $9.3 \pm 0.9$ & $7.5 \pm 0.3$ & $11.3 \pm 0.8$ & $6.9 \pm 0.3$ & $9.2 \pm 0.3$ & $6.7 \pm 1.2$ & $8.7 \pm 0.3$ & $11.9 \pm 0.8$ \\
\hline Sodium (mmol/dL) & $282.1 \pm 18.6$ & $293.8 \pm 19.0$ & $236.1 \pm 7.6$ & $165.6 \pm 32.2 * * *$ & $261.4 \pm 5.7$ & $108.6 \pm 7.1^{* * *}$ & $279.0 \pm 30.2$ & $184.0 \pm 11.3^{* * *}$ \\
\hline Potassium $(\mathrm{mmol} / \mathrm{dL})$ & $4.7 \pm 0.9$ & $5.3 \pm 0.4$ & $4.7 \pm 0.2$ & $4.1 \pm 0.1$ & $4.5 \pm 0.3$ & $3.5 \pm 0.1$ & $1.2 \pm 0.0$ & $2.5 \pm 0.1$ \\
\hline Phosphorus (mg/dL) & $6.2 \pm 0.3$ & $4.8 \pm 0.5$ & $5.5 \pm 0.8$ & $5.6 \pm 0.95$ & $5.4 \pm 0.8$ & $3.7 \pm 0.2$ & $3.7 \pm 0.4$ & $4.0 \pm 0.9$ \\
\hline Chloride $(\mathrm{mg} / \mathrm{dL})$ & $392.2 \pm 3.8$ & $416.5 \pm 37.5$ & $109.1 \pm 27.0$ & $67.1 \pm 26.9^{* * *}$ & $104.3 \pm 25.2$ & $59.0 \pm 27.0^{* * *}$ & $107.8 \pm 34.3$ & $51.0 \pm 29.4^{* * *}$ \\
\hline $\operatorname{AST}(\mathrm{UI} / \mathrm{L})$ & $159.4 \pm 15.9$ & $167.2 \pm 23.4$ & $148.9 \pm 4.6$ & $167.1 \pm 23.4$ & $184.9 \pm 42.4$ & $543.2 \pm 34.8^{* * *}$ & $140.4 \pm 9.0$ & $497.0 \pm 21.9^{* * *}$ \\
\hline ALT (UL/L) & $31.6 \pm 5.4$ & $34.7 \pm 6.1$ & $28.9 \pm 2.1$ & $31.9 \pm 5.4$ & $37.3 \pm 9.8$ & $57.0 \pm 8.4$ & $16.8 \pm 4.0$ & $34.8 \pm 5.2$ \\
\hline Total bilirubin (mg/dL) & $0.3 \pm 0.0$ & $0.2 \pm 0.0$ & $0.3 \pm 0.1$ & $0.3 \pm 0.0$ & $0.3 \pm 0.2$ & $0.5 \pm 0.1$ & $0.2 \pm 0.0$ & $0.8 \pm 0.0$ \\
\hline Direct bilirubin(mg/dL) & $0.6 \pm 0.0$ & $1.1 \pm 0.6$ & $0.3 \pm 0.1$ & $0.0 \pm 0.0$ & $0.2 \pm 0.8$ & $0.4 \pm 0.0$ & $0.2 \pm 0.0$ & $0.3 \pm 0.0$ \\
\hline BUN $(\mathrm{mg} / \mathrm{dL})$ & $17.0 \pm 1.1$ & $18.2 \pm 1.6$ & $16.8 \pm 5.3$ & $28.5 \pm 0.6$ & $17.0 \pm 1.7$ & $28.0 \pm 0.8$ & $28.3 \pm 0.9$ & $18.8 \pm 0.7$ \\
\hline Creatinine $(\mathrm{mg} / \mathrm{dL})$ & $2.7 \pm 0.2$ & $1.2 \pm 0.0$ & $1.1 \pm 0.2$ & $0.9 \pm 0.0$ & $1.17 \pm 0.7$ & $0.40 \pm 0.0$ & $11.9 \pm 6.5$ & $1.6 \pm 2.3$ \\
\hline Albumin $(\mathrm{mg} / \mathrm{dL})$ & $26.2 \pm 4.4$ & $26.1 \pm 2.1$ & $23.0 \pm 5.6$ & $26.3 \pm 1.2$ & 29.31 .6 & $25.9 \pm 3.5$ & $27.7 \pm 0.4$ & $29.7 \pm 2.1$ \\
\hline Total protein $(\mathrm{mg} / \mathrm{dL})$ & $62.1 \pm 1.0$ & $71.9 \pm 2.1$ & $65.4 \pm 9.6$ & $59.6 \pm 5.1$ & $64.0 \pm 1.0$ & $28.9 \pm 4.1$ & $69.4 \pm 0.2$ & $25.3 \pm 4.3$ \\
\hline Glucose $(\mathrm{mg} / \mathrm{dL})$ & $53.1 \pm 3.5$ & $56.0 \pm 3.20$ & $57.8 \pm 4.62$ & $46.3 \pm 6.8$ & $62.4 \pm 10.7$ & $122.0 \pm 20.1^{* * *}$ & $73.7 \pm 6.5$ & $124.7 \pm 5.5^{* * *}$ \\
\hline
\end{tabular}

Key: AST: aspartate aminotransferase; ALT: alanine aminotransferase; BUN: blood urea nitrogen; n: - number of goats.

*Differences in mean values significant at $\mathrm{p}<0.05$ (from baseline values and control).

$* *$ Differences in mean values significant at $\mathrm{p}<0.01$ (from baseline values and control).

*** Differences in mean values significant at $\mathrm{p}<0.001$ (from baseline values and control).

The variations could probably be attributed to differences in duration of rumen impaction as well as quantities of materials within the rumen between the current study and in reports of previous studies.

The significant changes in mean values of RBC, PCV and MCH observed in the goats with low quantity of plastic bags in this study, is in contrast with some previous reports indicating that impaction of the rumen with indigestible foreign bodies did not have any significant effects on the haematological parameters of the affected animals (Igbokwe et al., 2003; Mozaffari et al., 2009; Raoofi et al., 2012). Significant decrease in the values of these parameters have previously been reported in goats with indigestible foreign bodies (Elsa and Oneyili, 2002; Akirinmade \& Akirinde, 2012). However, in those previous reports, the type of indigestible foreign bodies as well as their duration in the rumen were not determined. Animals have a compensatory mechanism for accelerated production of RBCs in some situations and infections (Daramola et al., 2005). It has also been reported that increased PCV may occur due to contraction of the spleen as a result of increased levels of catecholamine which occur in stressful situations (Jain, 1986) and rumen impaction could be such a type of situation. In the current study, the sheep and goats were euthanized earlier than time would probably allow for significant changes to occur in haematological parameters as previously reported (Akirinmade et al., 1988; Remi-Adewunmi et al., 2004; Akirinmade \& Akirinde; 2012).

The higher mean values of platelets in sheep whose rumen were impacted with plastic bags than in the control may be attributed to stress. Stress may have triggered synthesis or release of more platelets into circulation (Jain, 
1986). However, the differences in platelet fluctuations in sheep and goats may be species variations in response to stress from impaction of the rumen. The responses of platelet to rumen impaction in sheep and goats has not been previously reported. The lack of significant changes seen in total and differential WBC counts in the current study are similar to previous reports in sheep and goats showing clinical impaction of the rumen with indigestible foreign bodies in natural ingestion of these materials (Mozaffari et al., 2009; Raoofi et al., 2012). This is probably because there was no infection or invasion by infective agents hence no physiological need for WBC production. However, goats appear to be more affected than sheep, even with less severe impaction of the rumen.

The observation of hyponatraemia in the goats is converse to the findings by Akinrinmade \& Akirinde (2012) who reported no changes in serum sodium levels in goats whose rumen were naturally impacted with foreign bodies. However, Igbokwe et al., (2003) reported low levels of serum sodium in sheep whose rumen had natural occurring impaction with indigestible foreign bodies, which is similar to observations in the current study. In these previous studies, the quantity and duration of indigestible foreign bodies in the rumen were not reported. The hyponatraemia could be due to anorexia, reduced feed intake, and/or loss of sodium in the urine and faeces (Ward et al., 1993; Radostits et al., 2009). Low sodium levels often occur in ruminants as a result of gastrointestinal losses through diarrhoea (Kaneko et al., 2008). Diarrhoea was one of the clinical symptoms observed in the animals implanted with plastic bags in the rumen and was more severe in the goats than the sheep. The animals also lost their appetite, which affected intake from the mineral salt licks that were provided. The cellular ionic sodium pump may have been compromised or obstruction of the passage of ingesta, subsequently leading to unavailability of nutrients in the impacted animals.

The low levels of serum chloride in sheep and goats implanted with plastic bags may be due to persistent anorexia throughout the experiment (Sethuraman \& Rathore, 1979). Hypochloraemia occurs in gastrointestinal tract obstruction, which results in failure of abomasal emptying with subsequent electrolyte sequestration in the abomasum including chloride ions (Radostits et al., 2009). The plastic bags implanted into the rumen did not only result in impaction and anorexia but also obstruction of the passage of ingesta. This subsequently led to unavailability of nutrients including chloride and was more severe in the sheep than goats.

The possible reason for higher values of aspartate aminotransferase observed in goats implanted with plastic bags could be degenerative or necrosis of the liver due to toxins from the damaged rumen mucosa (Gary, 2002) and as well as pressure atrophy of the liver. Elevations in AST are usually associated with necrosis of the cells of the liver, cardiac and skeletal muscles (Kaneko et al., 2008). All these organs and tissues were grossly affected in animals implanted with plastic bags in the rumen. Variations in the levels of aspartate aminotransferase in the serum of either sheep or goats with rumen impaction or indigestible foreign bodies in the rumen have not been previously reported. The low mean value of aspartate aminotransferase enzyme observed in the animals may have been influenced by low protein and energy balance levels due to inappetence that was observed in the sheep and the goats implanted with plastic bags in the rumen. Protein and energy balance levels have been associated with low levels of aspartate aminotransferase (Truchlinsky \& Grela, 1987). 
The increased serum glucose levels observed in goats implanted with plastic bags in this study may be due to the systemic stress induced by clinical rumen impaction leading to release of adrenocorticoids, which have glycogenolytic effect, causing hyperglycemia (Kaneko et al., 2008). In rumen impaction, volatile fatty acids are not synthesized in sufficient quantities to meet the animal's energy demand. So the animal depends on oxidation of glucose rather than volatile fatty acid metabolism (Kaneko et al., 2008). Similar findings of high serum glucose levels have been reported in buffaloes impacted with rumen foreign bodies (Hussain \& Uppal, 2012). However, low serum levels of glucose have also been reported in goats (Akinrinmade \& Akirinde, 2012) and cattle (Llewellyn, 1976) impacted with foreign bodies in the rumen, though the quantity of material impacting the rumen and duration of impaction were not reported. The hypoglycaemia in rumen impaction was attributed to high levels of free fatty acids and cholesterol associated with inadequate intake of feed, water deprivation and decreased glucose synthesis (Ramakrishna, 1994). This could possibly account for the slightly low serum glucose observed in the sheep in the current study.

\section{Conclusion}

Presence of plastic bags in the rumen caused changes in some haematological parameters in both sheep and goats. This was accompanied by hyponatraemia and hypochloridaemia in both species of animals. There were also increased levels of aspartate aminotransferase activity. These changes in haematological and biochemical parameters could be clinically significant in the well-being of small ruminants with plastic bag in the rumen.

\section{Conflict of Interest}

The authors confirm that there is no conflict of interest whatsoever regarding this manuscript.

\section{Acknowledgment}

We are grateful to TRECCAfrica and the University of Ghana for providing the funds for this work. Research assistants (Messers Charles Asava and Samuel Karanja) who assisted with data collection and the Faculty of Veterinary Medicine, Clinical Studies Department, University of Nairobi are appreciated for their support.

\section{REFERENCES}

Abdullahi, U.S., Usman, G. S. H \& Mshelia, T.A. (1984) Impaction of the rumen with Indigestible garbage in cattle and sheep reared within urban and sub-urban environment. Nig Vet J 13, 89 95.

Akinrinmade, J. F., Akusu, M. O \& Oni, S. O. (1988) Gastro-intestinal foreign body syndrome in sheep: A case report. Nig J Anim Prod 15, 145 -148 .

Akinrinmade, J. F \& Akinrinde, A. S. (2012) Prevalence of foreign body rumen impaction in slaughtered goats in Ibadan, Southwest Nigeria. Sahel J Vet Sci 11(1), 39 - 42.

Bakhiet, O. M. (2008) Studies on the rumen pathology of Sudanese desert sheep in slaughter house. Scientific Res and Ess 3 (7), 294 - 298.

Calfee, T \& Manning, T. O. (2002) Non-healing subcutaneous wound in the cats and proposed in the surgical management techniques. Clinical Techniques. Small Anim Prac 17 (4), 167-167.

Cheesbrough, M. (2000) District laboratories practice in tropical countries, Pt 2, Low Price Edition. Cambridge University Press, Cambridge, UK. pp. $220-228$. 
Daramola, J. O., Adeloye A. A., Fatoba, T. A. \& Soladoye A. O. (2005) Hematological and biochemical parameters of West African Dwarf goats: Livestock Res Rural Dev 17(8), 21-27.

Elsa, A. T \& Onyeli, P. A. (2002) Haematology of the Red Sokoto goats with rumen impaction. Online J Biol Sci, 2(8), 522 - 523.

Ghurashi, M. A. H., Seri, H. I., Bakheit, A.H., \& Ashwag, E. A. M. (2009) Effect of surgical removal of foreign body from goat's rumen with special reference to the prevalence of foreign body in goats in Southern Dafur. Aust $J$ Basic Appl Sci 3(2), $664-668$.

Gary, F. B. (2002) Indigestion in ruminants. Large animal internal medicine. $3^{\text {rd }}$ edition. Smith E.D and Mosby B.P Inc, Philadelphia, USA. pp. 748.

Gyang, E. O. (1991) Introduction to Large Animals Surgery. Ahmadu Bello University Press, Zaria, Nigeria. pp. $120-125$.

Hailat, N., Nouh, S., Al-Darraji, A., Lafi S.F., AlAni, F.A \& Al-Majali, A. (1997). Prevalence and pathology of foreign bodies (plastics) in Awassi sheep in Jordan. Small Rum Res, 24, 43 -48 .

Hendrickson, D.A. (2007). Techniques in large animal surgery. Third edition, Blackwell Publishing Ltd, Oxford, England.

Hussain, S. A \& Uppal, S. K (2012). Rumen impaction in buffaloes: A haemato-biochemical study. Indian J Anim Sci 82 (4), 369 - 373.

Igbokwe, I.O., Kolo, M.Y \& Egwu, G.O. (2003). Rumen impaction in sheep with indigestible

foreign body in the semi-arid region of Nigeria. Small Rum Res 49, 141-147.

Jain, N.C. (1986) Schalm's Veterinary Haematology, 4th Ed. Lea and Febiger, Philadelphia,

U.S.A. pp. $208-239$.
Kaneko, J. J., Harvey, J.W \& Bruss, M. L. (2008) Clinical Biochemistry of Domestic Animals. 6th edn. Academic Press, London.

Llewellyn, C. A. (1976) Acute impaction of the rumen in a herd of Friesian cows. Vet Rec, 99, $456-$ 457.

Mayer, D. Y., E. H. Coles \& Rich, L. J. (1992) Veterinary Laboratory Medicine. Interpretation and Diagnosis. W.B. Saunders Company, Philadelphia. pp. $328-329$.

Mozaffari, A. A., Olomi, M. M \& Vosouh, D. (2009) Unusual and severe ruminal impaction in a goatkid: clinical and radiographic findings. Iranian $J$ Vet Surg 4 (1, 2), $115-118$.

Omidi, A., Naeemipoor, H \& Hosseini, M. (2012) Plastic Debris in the Digestive Tract of Sheep and Goats: An Increasing Environmental Contamination in Birjand, Iran. Bull Environ Contam Toxicol, 88, $691-694$.

Otsyina, H. R., J. Nguhiu-Mwangi., E. G. M. Mogoa, P. G. Mbuthia \& W. O. Ogara (2014) A Retrospective Study on the Prevalence of Plastic Materials in the Rumen of Sheep and Goats in Nairobi, Kenya. Bull Anim Hlth and Prod Afri 62 (3), $197-205$.

Otsyina, H.R., Nguhiu-Mwangi, J., Mogoa, E.G.M., Mbuthia, P.G \& Ogara, W.O. (2015) Prevalence of Indigestible Rumen Foreign Bodies in Sheep and Goats at Dagoretti and Kiserian Abattoirs, Kenya. Inter J. Vet Med 4 (2), 75 - 80.

Radostitis, D.M., Gray, C.C., Blood, D.C \& Hinchelift, K.W. (2009) Veterinary Medicine: A Textbook of the diseases of cattle, sheep, pig, goats and horses, Saunders, London.

Randall, D., Burggren, W \& French, K. (2002) Eckert animal physiology: Mechanisms and adaptations. 5th ed. New York, NY: W.H. Freeman and Company. pp. $78-93$. 
Remi-Adewunmi, B.D., Gyang, E.O \& Osinowo, A.O. (2004) Abattoir survey of foreign

body rumen impaction in small ruminants. Nig Vet $\mathrm{J}$ 25, $32-38$.

RamaKrishna, K. V (1994) Clinical studies and therapeutic management of purulent pericarditis in bovines. Indian Vet $J$ 71, $400-402$.

Raoofi A, Namjoo A, Karimi AH \& Esfahani, M. A. (2012) A study of clinical signs,

hematological changes and pathological findings of experimental ingestion of soft foreign body (plastic rope) in goats. Small Rum Res 105, 351 - 354.

Roman, T. \& Y. Hiwot, (2010) Occurrence of rumen foreign bodies in sheep and goats slaughtered at the Addis Ababa Municipality. Ethiop. Vet $J 14$ (1), $91-100$.

Sileshi, N., Ramaswamy, V., Chandrashekhar, U \& Raja, N. (2013) Studies on Foreign Body Ingestion and their Related Complications in Ruminants Associated with Inappropriate Solid Waste Disposal in Gondar Town, North West Ethiopia. Inter J Anim Vet Adv 5 (2), 67 - 74.
Sethuraman, V \& Rathor, S. S. (1979) Clinical, haematological and biochemical studies in secondary indigestion in bovines due to traumatic reticulitis and diaphragmatic hernia. Indian J Anim Sci 49 (6), 703 - 706.

Tesfaye D., Yismaw S. \& Demissie, T. (2012) Ruminal and reticular foreign bodies in smallruminants slaughtered at Jimma Municipal abattoir, Southwestern Ethiopia. J. Vet Adv 2 (8), 434 439.

Truchlinski, J \& Greda, E. (1987) Alanine and aspartate transaminase and acid and alkaline phosphate activities in the blood serum in relation to the blood and energy levels in pigs' feed. Polskie arch weter 27 (2-3), $129-136$.

Vijaya, M., Reddy, B \& Sasikala, P. (2012) A review of foreign bodies with special reference to plastic pollution threat to livestock and environment in Tirupati rural areas. Inter J. Sci Res Pub 2 (12), $1-8$.

Ward, J. L., Smith, D. F., Fubini, S. C \& Grohn, Y. T. (1993) Comparison of 0.9, 3.6 and $7.2 \%$ sodium chloride for correction of experimentally induced hypochloremic, hyperkalemic metabolicalkalosis in sheep. Am J Vet Res 54, 1160 $-1169$. 